Boise State University

ScholarWorks

Geosciences Faculty Publications and

Presentations

Department of Geosciences

$12-2014$

\title{
Urban Seismology for Groundwater Characterization in a Developing Country: Challenges and Rewards
}

John H. Bradford

Boise State University

Kyle Lindsay

Boise State University

Steve Silliman

Gonzaga University

Nicaise Yalo

University of Abomey-Calavi

Moussa Boukari

University of Abomey-Calavi 


\title{
Urban seismology for groundwater characterization in a developing country: Challenges and rewards
}

\author{
John H. Bradford ${ }^{1}$, Kyle Lindsay ${ }^{1}$, Steve Silliman², Nicaise Yalo², and Moussa Boukari ${ }^{3}$
}

\section{Abstract}

The coastal city of Cotonou in the developing country of Bénin, West Africa, is a large population center that is facing a serious threat to the sustainability of its freshwater supply. The city relies on the Godomey aquifer for domestic water, but the aquifer is undergoing saltwater intrusion. This problem is likely to worsen without significant steps to improve management of the water supply. Aquifer continuity and saltwater flow paths are poorly understood, but that information is critical to ensure sustainable access to freshwater in this growing urban center. In January 2012, a two-year geophysical investigation was begun with the prime objective of using the seismic-reflection method to better understand the continuity of the primary aquifer units. That information then can be used to inform and improve the regional groundwater flow model. The project presented many challenges, both technical and cultural, including the language barrier, conducting fieldwork in the developing world with a limited budget, and the complicated logistics of acquiring seismic data in a congested urban environment. Despite these challenges, the seismic investigation was completed successfully, and results show that the aquifer system is substantially more complicated than previously thought. Critically, at least one paleochannel cuts through a substantial portion of the aquifer system and truncates multiple aquifer/aquitard boundaries. These boundary truncations appear to provide connected pathways among aquifers that previously were thought to be isolated and might explain recent hydrologic observations. Although the full impact of these findings is yet to be determined, it is clear that the seismic study has provided valuable information that improves the understanding of the system and ultimately will aid in management of the groundwater resource in Cotonou.

\section{Introduction - Motivation and background}

Of the eight goals identified by the United Nations Development Program (UNDP), the seventh is "Ensuring Environmental Sustainability." Within this framework, Target $7 \mathrm{c}$ states that by 2015 , the goal is: "Reduce by half the proportion of people without sustainable access to safe drinking water and basic sanitation." By 2012, 89\% of the global population had access to improved sources of drinking water. This number was up from 71\% in 1990 (United Nations, 2014) and met the UN's 2015 goal.

Although this is encouraging, a significant gap between urban and rural areas remains. This gap has focused much attention on improving the situation in rural areas. However, sustainable access to safe water in urban areas is by no means universal, and significant population centers remain at risk, particularly in the developing world. One such area is the coastal city of Cotonou in Bénin, West Africa.

History and geography. Bénin is bordered to the east by Nigeria, to the west by Togo, and to the north by Niger and Burkina Faso (Figure 1). To the south is the South Atlantic coast. The official language of Bénin is French, but local languages are in common use. Fon and Yoruba are spoken widely in the south, with more than half the population speaking Fon. Numerous other regional and local languages are spoken throughout Bénin.

Its position on the Bight of Bénin made Bénin a prime trading port in centuries past, and Bénin has a long and complex history. The first Europeans arrived in 1556, and by the 1600s, the slave trade had begun along the coast. In about 1650, the kingdom of Abomey (Dahomey) was established near the southern coast and became an active participant in the slave trade as the kingdom expanded. The kingdom captured slaves in conquered territories and exchanged them for Portuguese, French, and Dutch weapons.

In 1863, the first French protectorate was established with the king of Porto-Novo. In 1889, the last independent ruler

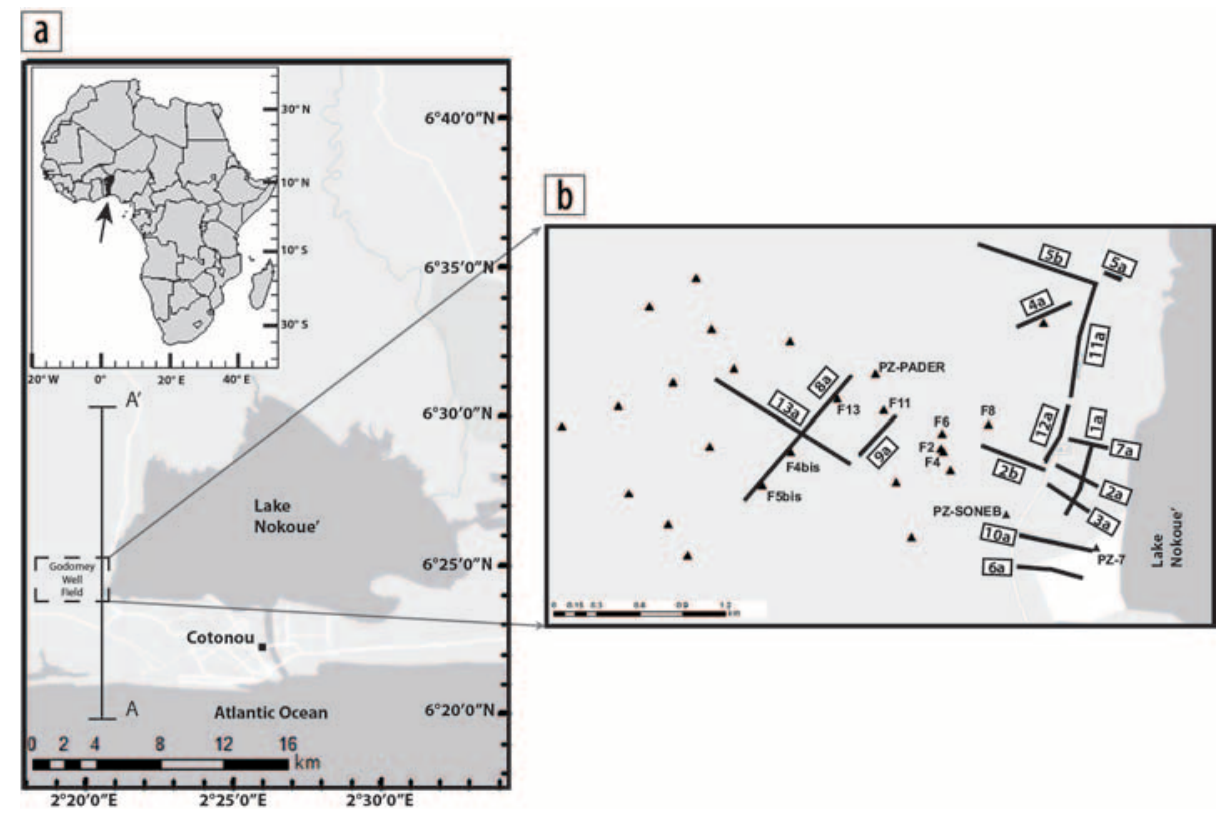

Figure 1. (a) Location of the Godomey well field and map of the field area, with inset showing the location of Bénin in West Africa. (b) Map of seismic coverage in the capture zone between Lake Nokoué and the Godomey well field. 
of Abomey sought to forcefully expel the French but was defeated, and in 1894, France colonized Dahomey. In 1904, Dahomey was incorporated into French West Africa. In 1958, the country gained independence from France, and after a period of political turmoil, it came under the leadership of a military government. Between 1989 and 1991, the country underwent a peaceful transition to a democratically elected government and became the Republic of Bénin.

Economy. According to the World Economic Forum, Bénin has become the most competitive economy in the West African Economic and Monetary Union because of several economic reforms enacted in the past decade. Despite these advances, however, Bénin

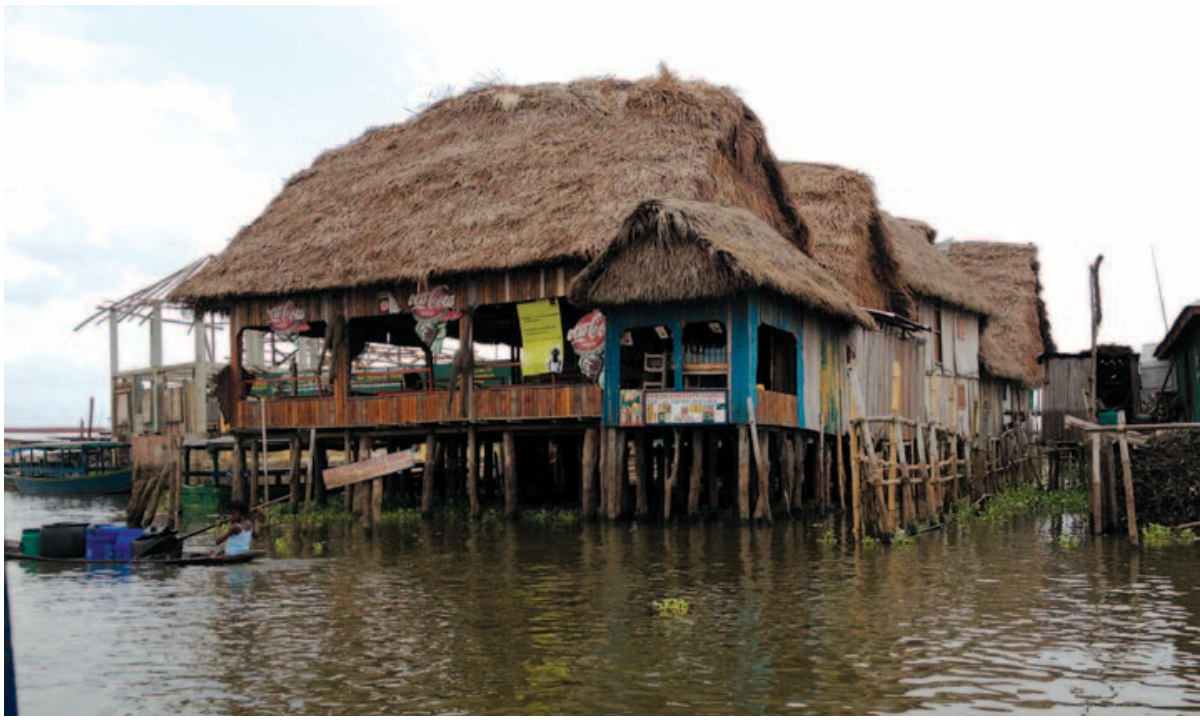

Figure 2. The lake city of Ganvié has a population of about 30,000 and is built entirely on stilts in the northern part of Lake Nokoué. remains economically underdeveloped, with a significant dependence on subsistence agriculture (Central Intelligence Agency, 2014). Bénin ranks 167 out of 187 countries on the UN's International Development Indicator, which integrates information such as economic growth, income, education, and health. This index also indicates that approximately $42 \%$ of the population in Bénin lives below the poverty threshold.

Hydrogeologic setting. Cotonou is Bénin's largest city, with a population of 1.5 to 2 million people. It is located along the Atlantic Coast and also is bordered by Lake Nokoué (Figure 1), which has extremely high salinity during the majority of the year. Lake Nokoué is a large shallow lake, reaching a maximum depth of $\sim 3 \mathrm{~m}$ during the rainy season. The lake is connected to the Atlantic Ocean via a shallow canal. Salinity in the lake is highly variable, ranging from less than $500 \mathrm{mg} / \mathrm{L}$ during the rainy season to greater than $30,000 \mathrm{mg} / \mathrm{L}$ during the dry season.

Further complicating the system is the city of Ganvié, which has more than 30,000 inhabitants, and other population centers that are built entirely on stilts within the lake (Figure 2). The presence of these lake cities and the fact that people rely heavily on the lake for fishing have resulted in severe manipulation of the lake for waste disposal, navigation, and fish farming.

The sole source of drinking water for Cotonou is the Godomey aquifer. The Godomey well field, the city's primary water-well field, lies approximately $5 \mathrm{~km}$ from the Atlantic coast but adjacent to Lake Nokoué (Figure 1). The well field consists of 20 wells that withdraw water from one or more of three semiconfined aquifers ranging in depth from 30 to $180 \mathrm{~m}$.

The current annual rate of urbanization in Bénin is approximately $4 \%$. The growth of the urban population has necessitated an increase in the pumping rate from the Godomey well field. Since 1990, the rate has increased steadily at about $900,000 \mathrm{~m}^{3 /}$ $\mathrm{yr}^{2}$. The increased rate has been accommodated by adding new wells at progressively increasing distances from Lake Nokoué. Increased pumping has been accompanied by an increase of salinity in the wells (Figure 3).

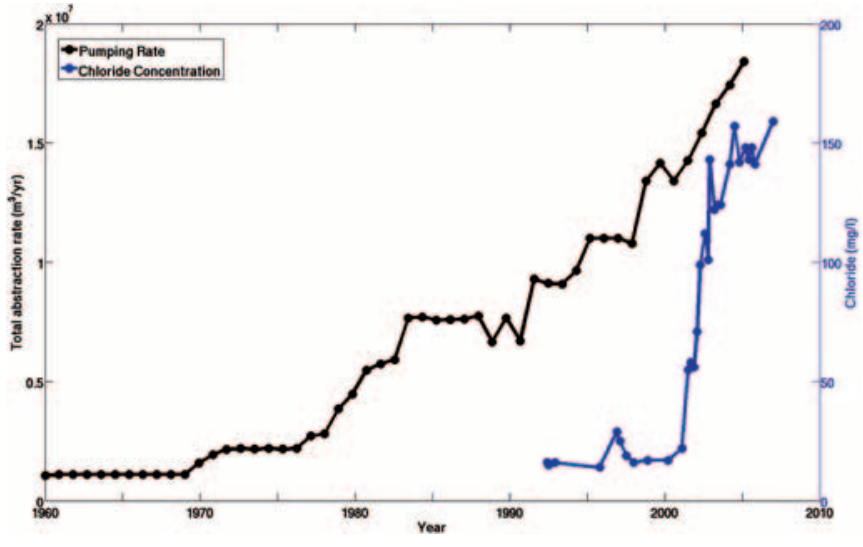

Figure 3. Evolution of the pumping rate in the Godomey well field (black) and chloride concentration in well F11 (blue). The pumping rate of the Godomey well field has increased an average of about $900,000 \mathrm{~m}^{3} / \mathrm{yr}^{2}$ since 1990 and has been accompanied by a rapid increase in chloride concentration beginning in 2000 .

There are two potential sources of the increasing salinity in the wells: (1) the Atlantic Ocean and (2) Lake Nokoué. Several of the deeper aquifer units extend beneath the Atlantic and therefore might be connected hydraulically to ocean waters. However, the wells closest to the ocean give no indication of increased salinity in the deeper aquifers. Conversely, all the wells that show increased salinity are close to Lake Nokoué.

In an effort to understand this large, complex system, an initial groundwater model was developed (Boukari et al., 2008) and then was improved through interpretation of the structure of the local geology (Silliman et al., 2010). Although not yet at the stage of a quantitative management tool, the groundwater model provides general information about the system and can be used to identify areas where further study is needed. For example, the model indicates that there is a groundwater divide between the ocean and the Godomey well field, consistent with observations that show little seawater encroachment from the south.

In addition, the model predicts that increased pumping will result in greater recharge being derived from the western part of 
Lake Nokoué. That is consistent with observations of increased salinity in the wells nearest to the lake. The combined field observations and numerical modeling indicate that Lake Nokoue is the likely source of saline intrusion into the Godomey aquifer system.

Although intrusion of saline waters from Lake Nokoue is the immediate threat to the sole source of drinking water for Cotonou, rising levels of chloride in shallow rural wells near the coast indicate that the encroachment of seawater into the shallowest aquifer might have begun, and that risk likely will increase as the groundwater resource is stressed increasingly. In addition, urbanization is resulting in increased development in the immediate vicinity of the Godomey well field, leading to greater risk of an-

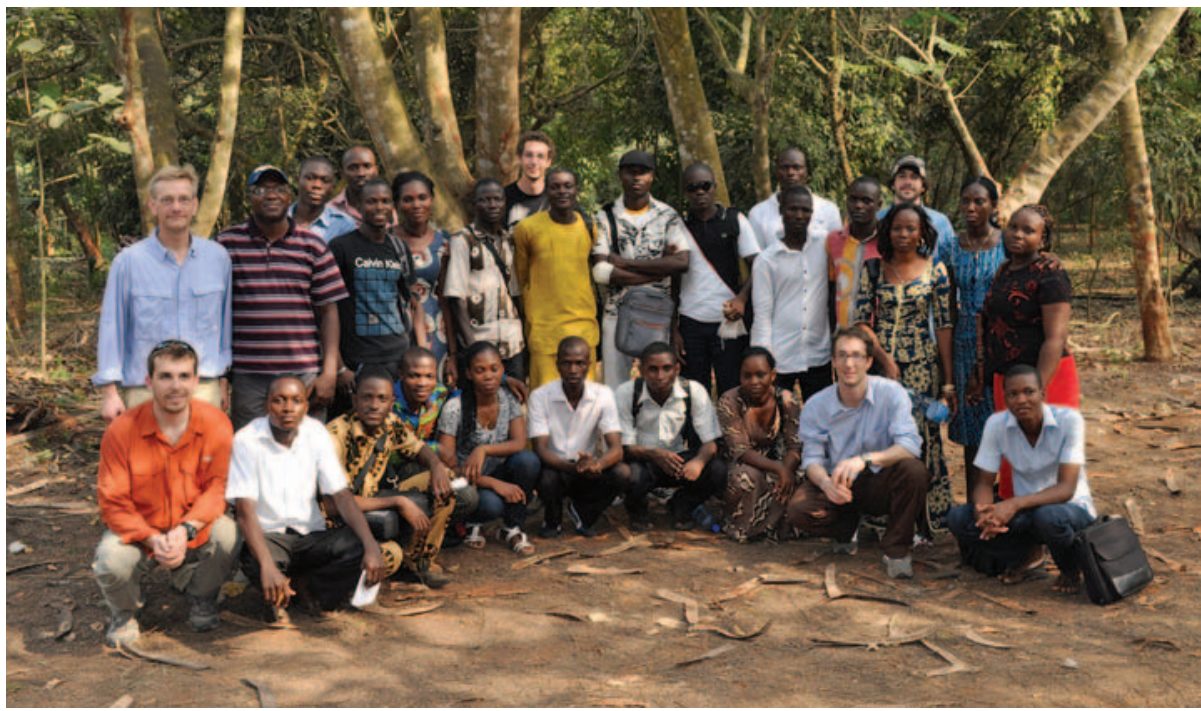

Figure 4. Students and faculty in the Geoscientists Without Borders short course on hydrogeophysics, University of Abomey-Calavi, Bénin, January 2013.

thropogenic release of hazardous groundwater contaminants.

In light of the various factors conspiring to endanger the drinking-water supply, it is critical that good management decisions are made now to sustain a viable source of freshwater for this growing urban area. The management plan must actively minimize the encroachment of saline water from Lake Nokoué while simultaneously mitigating the risk of seawater intrusion from the south and hazardous-chemical contamination related to increased development.

As noted by Silliman et al. (2011), the key management questions related to sustainability of the Godomey well field are "(i) for what period of time can the aquifer be expected to provide water for this urban population, (ii) what sources of contamination represent the most severe threats to this groundwater resource, (iii) what hydrologic properties of the recharge zones and deep aquifer system need to be more thoroughly characterized to assist in modeling this groundwater system, and (iv) what hydrologic properties of the recharge zones are likely to be impacted by climate change, population migration, or changing land-use practices."

Silliman et al. (2011) conclude that the current groundwater model and field-characterization efforts have not yet reached the level at which sound, data-driven management decisions can be made. Substantially greater characterization, coupled with refined groundwater modeling, is needed.

\section{Cultural and operational challenges}

Student involvement. A key component of the project was the involvement of students in all aspects from data acquisition to processing and interpretation. Of several objectives for student involvement, perhaps the two most important were (1) to provide cross-cultural interaction between students from the United States and Europe and students from Bénin and (2) to provide training in hydrogeophysics to all students involved in the project. In addition, the involvement of students was critical to data acquisition, and the project could not have been completed without their hard work.

To facilitate interaction, students and faculty members traveling from outside Bénin were required to speak French or to study French prior to departure. The majority of the Béninois students also had English-language training, which facilitated communication. At the beginning of each field season, a two- to three-day short course on seismic methods in hydrogeophysics was given in French at the University of Abomey-Calavi. European and U. S. students participated in the course along with their Béninois counterparts (Figure 4). After the short course was completed, students and faculty members were deployed to the field for seismic data acquisition.

Fieldwork was conducted through the crowded neighborhoods of Godomey on the northern outskirts of Cotonou. This provided the opportunity for close interaction with local residents, most of whom spoke French, but some spoke only the local language. The Béninois students not only helped with fieldwork but also served as ambassadors and interpreters as we worked through the city. Our interactions with locals were universally positive, and that was one of the truly rewarding aspects of the project (Figure 5). In addition, it was clear that residents were cognizant of the problem of saltwater intrusion, and they welcomed us and were interested in our work.

Operational challenges. Our initial field project consisted of land seismic-reflection acquisition along a set of profiles that ranged in length from $<200 \mathrm{~m}$ to greater than $1.5 \mathrm{~km}$ (Figure 1). Logistics for the seismic reflection were complicated by the necessity of conducting the work in a congested urban area (Figure 6). Road surfaces were highly variable, and many were not amenable to the planting of geophones. Heavy traffic and associated safety concerns for the seismic crew further limited seismic coverage. Where seismic acquisition was feasible, the roads typically ran through crowded neighborhoods with many roadside shops, along with heavy foot and vehicle traffic (Figure 7). Those challenging conditions limited seismic coverage to a somewhat sparse and irregular coverage grid (Figure 1).

In addition to logistics, operations were challenging relative to expectations of those who were used to conducting fieldwork in Western countries. Shipping equipment and supplies in and out of the country was difficult, and it was essential to travel with backups 
for all technical components. Gathering basic supplies such as batteries and work gloves was often a time-consuming task because many items taken for granted in the developed world are not as readily available and sometimes surprisingly expensive. Nevertheless, with a bit of patience and willingness to reset expectations, the work was completed within both the time and monetary budgets.

To balance the challenges, some aspects of the work were amazingly easy. For example, on our last field campaign, our home-built seismic source broke. At 6 P.M., we had a new piece machined and installed in less than 30 minutes, in the open air at a busy Cotonou intersection. Finally, it must be said that the Béninois students were exceptionally resourceful and hardworking. This smoothed field acquisition because numerous equipment repairs were made on the fly while the crew collected large amounts of data in a relatively short period.

\section{Seismic data acquisition and processing}

Data were acquired with five 24-channel Geometrics Geode seismographs, 3-m geophone spacing, and 6-m source spacing in an off-end geometry. The source was a $10-\mathrm{kg}$ sledgehammer, and we used $10-\mathrm{Hz}$ vertical geophones. Approximately 10 linear $\mathrm{km}$ of data was acquired along the 15 profiles shown in Figure 1.

Along all lines, we contended with high levels of coherent noise that included heavy vehicle traffic, small local grain mills in many neighborhoods (Figure 8), and constant pedestrian traffic. Despite those sources of noise, near-optimal surface conditions resulted in excellent source and receiver coupling with good data quality. Although coherent noise masked reflections in the raw records, most of the cultural noise was low frequency $(<40 \mathrm{~Hz})$, and a spectral-balancing filter over the dominant band of reflection energy (40 to $300 \mathrm{~Hz}$ ) substantially enhanced the reflections.

The processing flow required to produce good-quality stacked sections was most basic and included automatic gain control (often necessary in such high-noise environments), a top mute to remove the first-break refraction, normal-moveout velocity analysis, elevation statics, stacking, and migration.

\section{Results}

Despite the high levels of coherent noise, the simple processing flow produced high-quality stacked sections that showed

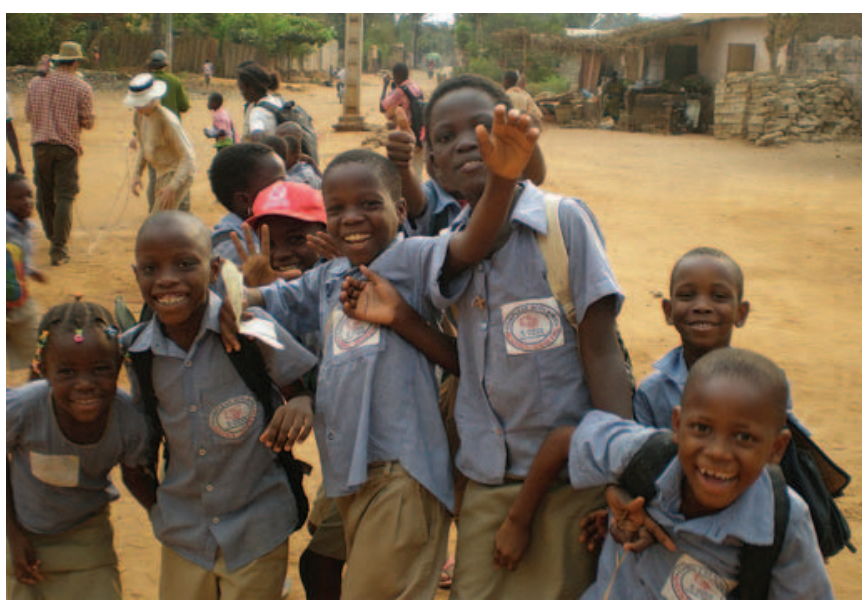

Figure 5. Interacting with local residents: Our seismic line was adjacent to a school, and when these schoolchildren were let out for the day, they took great interest in the seismic survey. reflections at a depth of as much as $1 \mathrm{~km}$ and revealed key characteristics of the Godomey aquifer. The base of the aquifer system is at a depth of $\sim 180 \mathrm{~m}$ or traveltime of 200 to $250 \mathrm{~ms}$ (Figure 9). High-amplitude, laterally continuous reflections above $200 \mathrm{~ms}$ correlate with thin clay aquitards identified in well lithologic logs. Those aquitards are separated by relatively thick sandy aquifers.

Although the data throughout the survey generally show significant variability of interbedded aquifers and aquicludes, perhaps the feature with the greatest hydrologic significance that we found is a set of paleochannels approximately $60 \mathrm{~m}$ deep and as much as $500 \mathrm{~m}$ wide (e.g., along line 10a, Figures 1 and 9). The channels, which cut through the units that comprise the aquifer/aquiclude system of the larger Godomey aquifer (Figure 9), run roughly north-south along the eastern boundary of the well field and between the well field and the capture zone in the southwestern part of Lake Nokoué. The channels cut multiple aquiclude/aquitard boundaries, providing a connected pathway among aquifers previously thought to be confined.

The presence of these channels might explain recent pumping data, which indicate that the shallow and deep aquifers are connected hydrologically. Because the channels lie between the primary recharge zone of Lake Nokoué and the Godomey well field, they likely have a major impact on mixing between multiple aquifer levels and the flow paths from the lake to the well field. Ongoing work is focused on integrating the channel system explicitly into the hydrologic model.

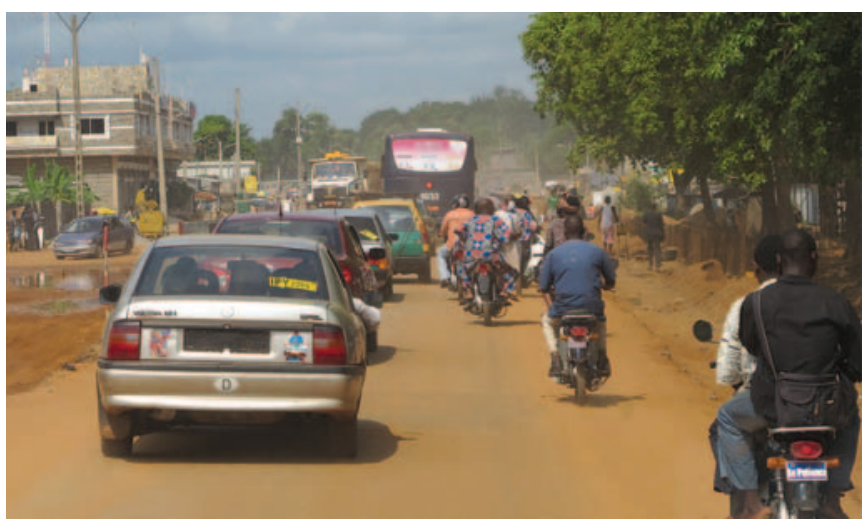

Figure 6. Streets in Cotonou consist of variable surfaces and are congested. Restricted access and safety concerns limited our seismic coverage. After Bradford and Lindsay, 2013, Figure 2.

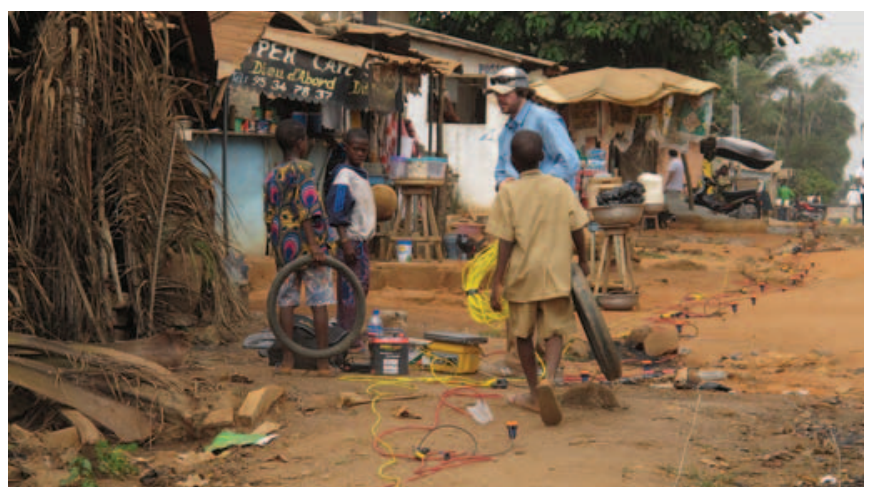

Figure 7. This photo shows a typical roadway used in acquisition. Limited access required that seismic lines be placed among small roadside businesses and homes. Heavy foot and vehicle traffic produced substantial coherent seismic noise. After Bradford and Lindsay, 2013, Figure 3. 

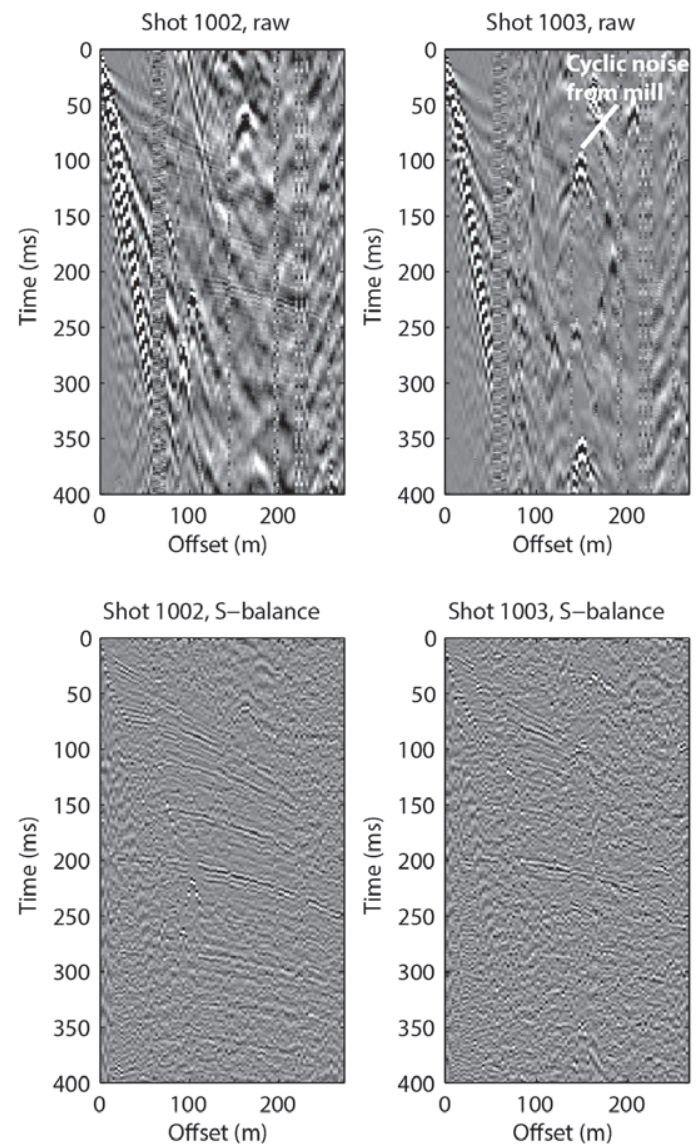

Figure 8. Shots along line 10a (Figure 1) illustrate the variable data quality observed throughout the survey area. In shot 1003, noise from a small grain mill is evident as a repetitive source. Shot 1002 shows noise from the same location but with lower amplitude. High-frequency reflections are evident in the raw shot 1002 record but are obscured in shot 1003. The spectral-balancing filter enhances the reflections in both records, but shot 1002 is clearly cleaner. After Bradford and Lindsay, 2013, Figure 5.

\section{Conclusions}

Conducting a field geophysics project in the developing world is fraught with challenges, particularly in an urban environment. These include potential language barriers, difficulties in shipping and repairing equipment, traffic congestion, and differing cultural and safety expectations. Despite such challenges, the intercultural exchange between students and faculty members is invaluable, and the willingness of all parties to work diligently toward the project objectives meant that the project in Cotonou was completed on time and within budget.

We found that the Godomey aquifer system is substantially more complicated than previously mapped. The complexities must be included in the hydrologic model if it is to have value as a predictive management tool. Some large features such as the incised paleochannel system can be mapped directly, but a geostatistical analysis will be required to extract information about the smaller-scale heterogeneity. The seismic study substantially enhanced our understanding of the aquifer system, and the information gleaned from it will help to inform future management decisions. IIL:

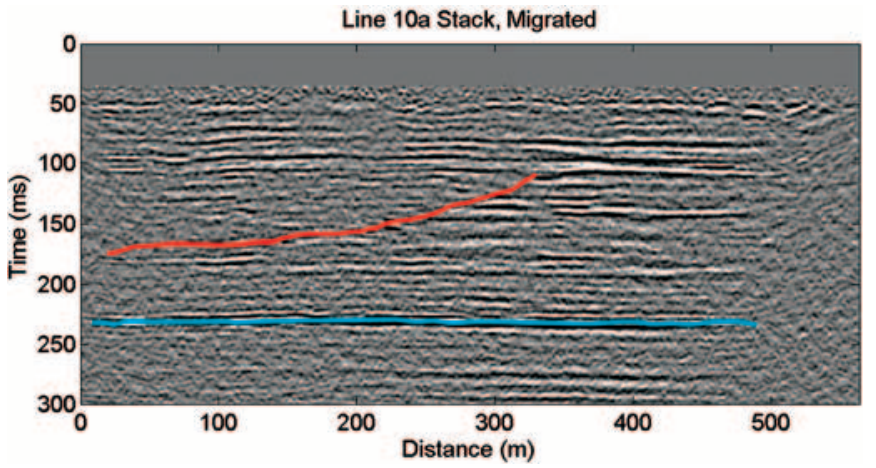

Figure 9. In line 10a, the eastern flank of the paleochannel is observed clearly as an erosional surface that cuts the aquifer system (red). The base of the aquifer system is defined by a high-amplitude continuous reflection (blue). After Bradford and Lindsay, 2013, Figure 6.

Editor's note: Geoscientists Without Borders is a registered trademark of the SEG Foundation.

\section{Acknowledgments}

The Society of Exploration Geophysicists program Geoscientists Without Borders generously funded this work through a grant to Boise State University. Additional support was provided by CGG Veritas, Boise State University, the University of Nice Sophia Antipolis, Micron Technology, Mala Geosciences, and Delta Airlines. Additional thanks go to Dylan Mikesell, who led the team from the University of Nice Sophia Antipolis; Thomas Blum, who gave the lectures for the January 2013 short course; and all the students from the United States, France, and Bénin who helped with data acquisition.

Corresponding author: jbradfor@boisestate.edu

\section{References}

Boukari, M., P. Viane, and F. Azonsi, 2008, Three-dimensional modeling of a coastal sedimentary basin of southern Bénin (West Africa), in S. M. A. Adelana and A. M. MacDonald, eds., Applied groundwater studies in Africa: IAH Selected $\mathrm{Pa}-$ pers on Hydrogeology, 13, 437-456.

Bradford, J. H., and K. Lindsay, 2013, Seismic imaging to manage salt water intrustion in Bénin, West Africa: Challenges in an urban, coastal environment: 83rd Annual International Meeting, SEG, Expanded Abstracts, 5212-5216, http://dx.doi. org/10.1190/segam2013-1481.1.

Central Intelligence Agency, 2014, The world factbook, https:// www.cia.gov/library/publications/the-world-factbook/geos/ bn.html, accessed 23 June 2014.

Silliman, S. E., B. I. Borum, M. Boukari, N. Yalo, S. Orou-Pete, D. McInnis, C. Fertenbaugh, and A. Mullen, 2010, Issues of sustainability of coastal groundwater resources: Bénin, West Africa: Sustainability, 2, 2652-2675, http://dx.doi.org/10.3390/su2082652.

Silliman, S. E., M. Boukari, L. Lougbegnon, and F. Azonsi, 2011, Overview of a multifaceted research program in Bénin, West Africa: An International Year of Planet Earth groundwater project, in J. A. A. Jones, ed., Sustaining groundwater resources: A critical element in the global water crisis (International Year of Planet Earth): Springer, 175-186.

United Nations, 2014, The millennium development goals report 2014. 